\title{
PROGRAMACIÓN DE LA CONSTRUCCIÓN DEL TERCER ANILLO DE MUROS ANCLADOS DE UNA EDIFICACIÓN APLICANDO EL MÉTODO DE LÍNEAS DE BALANCE
}

\author{
Steven Paredes_Gutierrez, Hubert Torres_Tacuri, Rosmery Gómez_Minaya
}

\section{RESUMEN}

En la industria de la construcción, planificar y controlar el cronograma de obra son importantes, debido a que se cometen errores al realizar la programación inicial del proyecto, ya que durante la ejecución de la obra se generan retrasos entre actividades al usar métodos convencionales como CPM y PERT por una ineficiente gestión del tiempo. Este trabajo de investigación determina los beneficios en la gestión del tiempo al aplicar la programación por Líneas de Balance (LDB), en la construcción de muros anclados del tercer anillo de una edificación, dado que este método facilita la visualización de actividades en el cronograma, lo que ayuda a identificar los conflictos entre las tareas antes de que estos se realicen. Se analiza las velocidades y rendimientos, de datos obtenidos de los cronogramas real y meta llevados a cabo con el método de LDB, para analizar la diferencia de velocidades representándolo en porcentajes, donde se evalúa aquellos sectores y partidas que generan retrasos o adelantos en el cronograma. Con base en los resultados obtenidos, el método LDB mejora la gestión del tiempo en $3.57 \%$ con relación a las velocidades de avance, empleando mejoras en el ratio y mano de obra a través del control del cronograma por porcentajes de avance de las actividades relativo a lo planificado. Además, se implementa un diagrama de flujo para una mejor aplicación de las LDB, en el control del proceso de las actividades de muros anclados, esto a diferencia de otros estudios previos realizados.

Palabras Clave: Líneas, Balance, LDB, Cronograma, Tiempo, Planificar, Controlar.

DOI: 10.23881 /idupbo.020.1-13i 